\title{
Acute and Subchronic Toxicities and Safety Pharmacology Studies of a Bacillus Subtilisin in Dogs
}

\author{
Shuai Xiao, ${ }^{a, \#}$ Yanshan Dong, ${ }^{a, b,}$ Kunkun $\mathrm{Hu},{ }^{b}$ Dingbang Hu, ${ }^{a}$ Li Zhou, ${ }^{a, c}$ and Yefu Wang ${ }^{*, a}$ \\ ${ }^{a}$ State Key Laboratory of Virology, Wuhan University School of Life Sciences; 299 Bayi Road, Wuhan 430072, China: \\ ${ }^{b}$ Wuhan Zhenfu Pharmaceutical Co., Ltd.; 388 Gaoxin 2nd Road, Wuhan 430072, China: and ${ }^{c}$ Animal Biosafety Level \\ III Laboratory, Wuhan University School of Medicine; 299 Bayi Road, Wuhan 430072, China.
}

Received August 18, 2020; accepted November 19, 2020; advance publication released online December 4, 2020

\begin{abstract}
Subtilisin NAT, a Bacillus subtilisin, is widely applied as a functional food and considered to be one of the most exploitable potential oral thrombolytic agents. Subtilisin QK, another Bacillus subtilisin, is a serine protease fermented by Bacillus subtilis 02 and has a better thrombolytic effect. Therefore, subtilisin QK is typically used for evaluating the safety of Bacillus subtilisins. Here, we conduct several good laboratory practice (GLP)-compliant studies in non-rodent animal, i.e., in Beagle dogs, including acute toxicity, subchronic toxicity, and safety pharmacology studies. No adverse effects were evident in the acute and 28-d subchronic toxicity studies at doses up to $40000 \mathrm{FU} / \mathrm{kg}$ and $16000 \mathrm{FU} / \mathrm{kg} / \mathrm{d}$, respectively. In evaluating the pharmacological safety of up to $2000 \mathrm{FU} / \mathrm{kg}$ subtilisin $\mathrm{QK}$, we found no significant differences between the electrocardiograms, blood pressures, and respiration of beagle dogs. These findings suggest the safety of Bacillus subtilisin, providing reliable pharmacological and toxicological data for its development and popularization as a functional food and drug.
\end{abstract}

Key words Bacillus subtilisin; subtilisin QK; acute toxicity; subchronic toxicity; safety pharmacology

\section{INTRODUCTION}

Coronary heart disease, stroke, and venous thromboembolism are serious threats to human health, with thrombosis being one of the major causes of these diseases. ${ }^{1)}$ However, safe and effective oral thrombolytics for the preventing and treating these diseases are unavailable. ${ }^{2)}$ Bacillus subtilisins, a class of serine proteases secreted by Bacillus subtilis, ${ }^{3,4)}$ are considered to effective thrombolytic agent with great exploitable potential, ${ }^{5,6)}$ owing to their ability to efficiently degrade cross-linked fibrins. ${ }^{3)}$ Recently, their importance in the improvement of blood circulation is gradually increasing. ${ }^{7.8)}$ For example, subtilisin NAT, is widely used as a functional food for preventing cardiovascular and cerebrovascular diseases. ${ }^{8,9)}$

Subtilisin NAT is a fibrinolytic enzyme derived from natto fermented with Bacillus subtilis NAT and was officially named "nattokinase" by Sumi in 1987.,10) Subtilisin NAT is a serine protease with a good of thrombolytic effect. In vitro, the same molar amount of subtilisin NAT degraded cross-linked proteins six times more efficiently than plasmin. ${ }^{11)}$ Additionally, its efficiency at degrading blood clots was $>4-5$ times that of plasmin. ${ }^{11)}$ Subtilisin NAT also reportedly promotes thrombolysis in vivo. For example, it efficiently dissolved the thrombus in a tail vein thrombosis rat model. ${ }^{12,13)}$ It also lysed the thrombus in a chemically induced rat carotid artery model more effectively than plasmin. ${ }^{14)}$ Subtilisin NAT not only directly degrades cross-linked fibrins ${ }^{11)}$ but also activates endogenous urokinase-type plasminogen activator (u-PA) and tissue plasminogen activator (t-PA), which further activate plasmin, which enhances fibrinolysis. ${ }^{13,15)}$ Additionally, it can reduce coagulation factor VII and VIII levels in humans and inhibit platelet aggregation, thus, reducing the risk of throm-

${ }^{\#}$ These authors contributed equally to this work. bosis. $^{16,17)}$ A couple of recent clinical trials have shown that oral subtilisin NAT can improve blood circulation and reduce cardiovascular disease risk. ${ }^{18,19)}$ Because of its significant thrombolytic and anticoagulation effects, subtilisin NAT is a widely used functional food worldwide. Despite this, toxicological data on Bacillus subtilisin remain limited, with only a few reports of the toxicity of subtilisin NAT in mice and Sprague-Dawley (SD) rats. Its maximum daily tolerance dose is reportedly $480000 \mathrm{FU} / \mathrm{kg} / \mathrm{d}$ in mice and $21900 \mathrm{FU} / \mathrm{kg} / \mathrm{d}$ in rats. ${ }^{19)}$ A single oral administration of $49400 \mathrm{FU} / \mathrm{kg}$ subtilisin NAT in rats resulted in no obvious toxicity. ${ }^{19)}$ The assessment of the potential toxicity of Bacillus subtilisin is limited by data unavailability. Therefore, this study aimed at assessing the safety of Bacillus subtilisin in beagle dogs using subtilisin QK.

Subtilisin QK, a serine protease produced by the fermentation of Bacillus subtilis QK02, is highly homologous with subtilisin NAT $\left(98.78 \%\right.$ identical) ${ }^{20)}$ Similar to subtilisin NAT, subtilisin QK consists of 275 amino acid residues $(\mathrm{MW}=27.8 \mathrm{kDa}){ }^{20)}$ However, subtilisin QK reportedly has a more effective thrombolytic effect. It degrades cross-linked fibrins and has strong thrombolytic capacity in thrombotic mouse models. ${ }^{21,22)}$ In the present study, a relatively large dose of subtilisin QK was used to conduct acute toxicity, repeated dose toxicity, and safety pharmacology studies in non-rodent animals, i.e., beagle dogs under good laboratory practice (GLP) conditions. This study aimed at providing reliable pharmacological and toxicological data for Bacillus subtilisin, to aid the popularisation of their use as functional foods and drugs.

\section{MATERIALS AND METHODS}

Materials and Dose Selection Subtilisin QK, derived

*To whom correspondence should be addressed. e-mail: wangyefu@whu.edu.cn 
from the liquid fermentation of Bacillus subtilis QK02, was provided by Wuhan Zhenfu Pharmaceutical Co., Ltd. (Wuhan, China). The fermentation broth was made into a powder by centrifugation, microfiltration, ultrafiltration concentration, and spray drying. The isolated enzyme was identified using the fibrin plate method. Meanwhile, the microbial limit, $\mathrm{pH}$, biological activity, moisture, molecular weight, protein content, and percentage of the spray dried powder were evaluated. Analytical data from tests on three batches of subtilisin QK are presented in supplementary Table 1. Zoletil (6W9K, Virbac, France) was used to anesthetize beagle dogs in all experiments (the injection dose was $15 \mathrm{mg} / \mathrm{kg}$ body weight and the injection volume was $0.3 \mathrm{~mL} / \mathrm{kg}$ body weight). According to the low dose of mouse drug effect (1000 FU/kg), the equivalent dose of Beagle dog is about $200 \mathrm{FU} / \mathrm{kg}$. In acute toxicity experiment, in order to obtain more toxicity data, the dose of this test is designed to be 20000 and $40000 \mathrm{FU} / \mathrm{kg}$, which were approximately 100 and 200 times the equivalent dose of Beagle dogs. In subchronic toxicity test, the low, medium, and high doses were designed to be 1000, 4000, and 16000 FU/kg, respectively, which were approximately 5, 20, and 80 times the equivalent dose of Beagle dogs. In pharmacology safety test, the low, medium, and high doses were designed to be 200,500 , and $2000 \mathrm{FU} / \mathrm{kg}$, respectively, which were approximately $1,2.5$, and 10 times the equivalent dose of Beagle dogs.

Animal Husbandry and Maintenance Healthy 8-10-months-old female and male beagle dogs, were purchased from Qingdao Bolong Experimental Animal Co., Ltd. (Qingdao, China), and quarantined and fed for $35 \mathrm{~d}$, for adaptation. They were all housed in the common-level breeding room at the Suzhou drug safety evaluation and research center (animal license number: SYXK (Su) 2016-0042), maintained at $22 \pm 2{ }^{\circ} \mathrm{C}, 50 \pm 10 \%$ relative humidity, a $12 \mathrm{~h}: 12 \mathrm{~h}$ light and dark cycle, and $\geq 8$ minimum air change times per hour. All experimental procedures were conducted in conformity with institutional guidelines for the care and use of laboratory animals in Wuhan University, Wuhan, China, and conformed to the National Institutes of Health Guide for Care and Use of Laboratory Animals.

Acute Toxicity Study Six beagle dogs were randomly allocated to three groups (a female and a male in each group). Each was administered a single dose of 0 (control), 20000, or $40000 \mathrm{FU} / \mathrm{kg}$ subtilisin QK (enteric-coated capsule). Clinical signs of toxicity were very closely monitored at 1,3 , and $6 \mathrm{~h}$ post administration, and twice daily during the $14-\mathrm{d}$ observation period. The body temperatures of all animals were recorded before administration and $1,3,6$, and $24 \mathrm{~h}$ post administration. The body weights of all animals were recorded before administration and 2, 7, and $14 \mathrm{~d}$ post administration. Electrocardiography, haematology, blood biochemistry and coagulation were performed before administration, and 2 and $14 \mathrm{~d}$ post administration. All blood samples were evaluated within $2 \mathrm{~h}$ of collection. On day 15 , all animals were euthanised by exsanguination after intramuscular anaesthesia and were subjected to gross necropsy.

\section{Subchronic Toxicity Study}

\section{Experimental Design}

Forty beagle dogs were randomly assigned to four groups (5 females and 5 males in each group). They were administered 0 (control), 1000, 4000, or $16000 \mathrm{FU} / \mathrm{kg}$ subtilisin QK (enteric- coated capsules) daily for $28 \mathrm{~d}$. At the end of the dosing period (D29), 3 males and 3 females from each group were randomly selected for pathological examination. The remaining animals ( 2 males and 2 females in each group) were continuously monitored for $28 \mathrm{~d}$ (recovery period). At the end of the recovery period (rD29), all remaining animals were euthanised and pathologically examined.

Note: D0, before the dosing day; D1, first day of dosing; $\mathrm{rD1}$, first day of the recovery period (by analogy with other experimental data).

Clinical Observations and Measurements

Clinical signs of toxicity were monitored twice daily during the dosing and recovery periods. The food consumption of each animal was measured daily. The body weights of each animal were recorded on D0, D7, D14, D21, D28, rD7, rD14, $\mathrm{rD} 21$, and $\mathrm{rD} 28$. The body temperatures of each animal were recorded on D0, D14, D28, and $\mathrm{rD} 28$.

Ophthalmoscopy and Electrocardiography

The eyes (eyelid, conjunctiva, cornea, sclera, iris, pupil, lens, vitreous, and fundus) of each animal was examined with an eye examination slit lamp microscope and a binocular indirect ophthalmoscope on D0, D28, and rD28. On D0, D14, D28, and rD28, electrocardiogram of each animal was taken for heart rate, PR interval, QT interval, QRS interval, P wave, $\mathrm{R}$ wave, $\mathrm{T}$ wave, and ST interval by using electrocardiography (ECG-1103G Vet, Carewell, China). QTc were calculated using the equation $\mathrm{QTc}=\mathrm{QT}-0.087(\mathrm{RR}-1000)$.

Urinalysis

Urinalysis samples were collected from all animals on D0, D13, D27, and rD27, and analysed within $2 \mathrm{~h}$. Colour (CLO), pH, turbidity (TURB), nitrite (NIT), glucose (GLU), specific gravity (SG), occult blood (BLD), protein (PRO), bilirubin (BIL), urobilinogen (URO), and ketones (KET) were determined using a urine chemistry analyzer (AUTION MAX AX-4280, ARKRAY, Japan).

Haematology, Blood Biochemistry and Coagulation Parameters

On D0, D14, D28, and rD28, each animal was subjected to venous blood collection using ethylenediaminetetraacetic acid (EDTA)-K2 and sodium citrate-coated tubes, and an inert separating gel coagulant tube, chronologically. The blood samples collected in the EDTA-K2-coated tubes were analyzed for haematology using an auto-hematology analyzer (XT2000iV, SYSMEX CORPORATION, Japan). Na+, K+ and $\mathrm{Cl}-$ were determined using an electrolyte analysis instrument (XI-931T, Shenzhen City Kate Bio-Medical Electronics Co., Ltd., China). Blood biochemistry was determined using an automatic biochemistry analyzer (c8000, Abbott Laboratories, U.S.A.). The blood samples collected in sodium citrate-coated tubes. Plasma was separated for coagulation detection using an automated coagulation analyzer (STAGO STA-R Evolution, DIAGNOSTICA STAGO, France).

Histopathology

On D29 and rD29, 24 and 16 beagle dogs were individually euthanized by exsanguination after intramuscular anaesthesia, respectively. Their organs were then harvested for histological studies. Organ weights (brain, thymus, kidney, adrenals, thyroid, liver, spleen, testis, epididymis, uterus, ovaries) were recorded, and the relative organ weights were calculated using the formula relative organ weight $=$ absolute organ weight $(\mathrm{g}) /$ Body weight $(\mathrm{g}) \times 100 \%$. In addition, samples were collected 
from the sternum of all animals to take a bone marrow smear for bone marrow cell categorization and quantification.

Immunotoxicity

Blood biochemical analysis was used to determine white/ ball ratio and the levels of albumin, globulin, immunoglobulin $\mathrm{G}$ (IgG), immunoglobulin M (IgM), complement 3 (C3), complement $4(\mathrm{C} 4)$, and circulating immune complex (CIC). The $\mathrm{T}$ lymphocyte phenotype of Peripheral blood form each animal was determined using a flow cytometry (AFC2, Thermo Fisher Scientific, U.S.A.). White blood cells types, counts, and percentages were analysed to investigate the effects of subtilisin QK on peripheral blood leukocytes. The immune system of each animal (spleen, thymus, and lymph nodes) was subjected to gross pathological and histopathological examinations.

Pharmacology Safety Study Eight beagle dogs were randomly allocated to 4 groups (a female and a male in each group, according to the $4 \times 8$ Latin square design plan, as the supplementary Table 2), and administered a single dose of 0 (control), 200, 500, or $2000 \mathrm{FU} / \mathrm{kg}$ subtilisin QK (enteric- coated). After each administration, at least $7 \mathrm{~d}$ of washing period should be used before the next administration. During the four dosing cycles, electrocardiogram (ECG), blood pressure parameters, and respiratory parameters of each animal were measured using the emka PACK 4G telemetry system (emkaPACK 4G, EMKA Technologies, France). All animals were subjected to adaptive training prior to data collection. ECG values (heart rate, PR interval, QT interval, QRS interval, $\mathrm{P}$ wave, $\mathrm{R}$ wave, $\mathrm{T}$ wave, ST interval, and QTc) and respiratory parameters (respiratory frequency and tidal volume) were measured continually from $0.5 \mathrm{~h}$ prior to dosing until $24 \mathrm{~h}$ after dosing. Blood pressure (systolic and diastolic blood pressure) was measured $15 \mathrm{~min}$ prior to dosing, and at $0.5,1,2,4,6,8$, and $24 \mathrm{~h}$ after dosing. ECG, blood pressure, and respiratory parameters measured at the mentioned time points were processed using the ECG auto analysis software of emka PACK 4G telemetry system (emkaPACK 4G, EMKA Technologies).

Data Processing The Levene's test was used to test the homogeneity of variance. If the variance was uniform
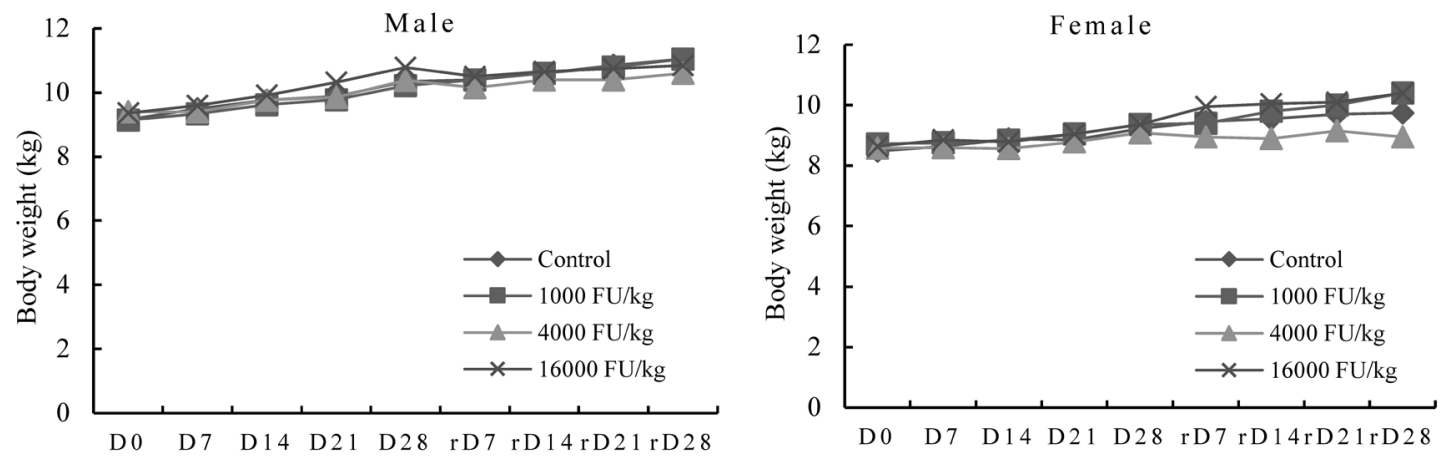

Fig. 1. Mean Body Weight of Beagle Dogs Administration with Subtilisin QK for $28 \mathrm{~d}$ and $28 \mathrm{~d}$ Recovery
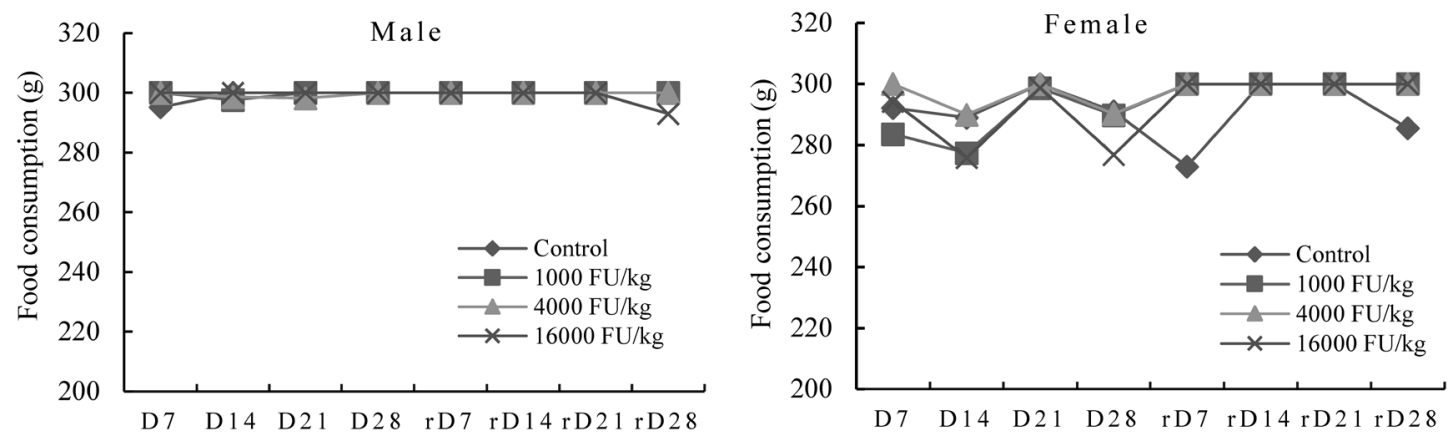

Fig. 2. Mean Food Consumption of Beagle Dogs Administration with Subtilisin QK for $28 \mathrm{~d}$ and $28 \mathrm{~d}$ Recovery
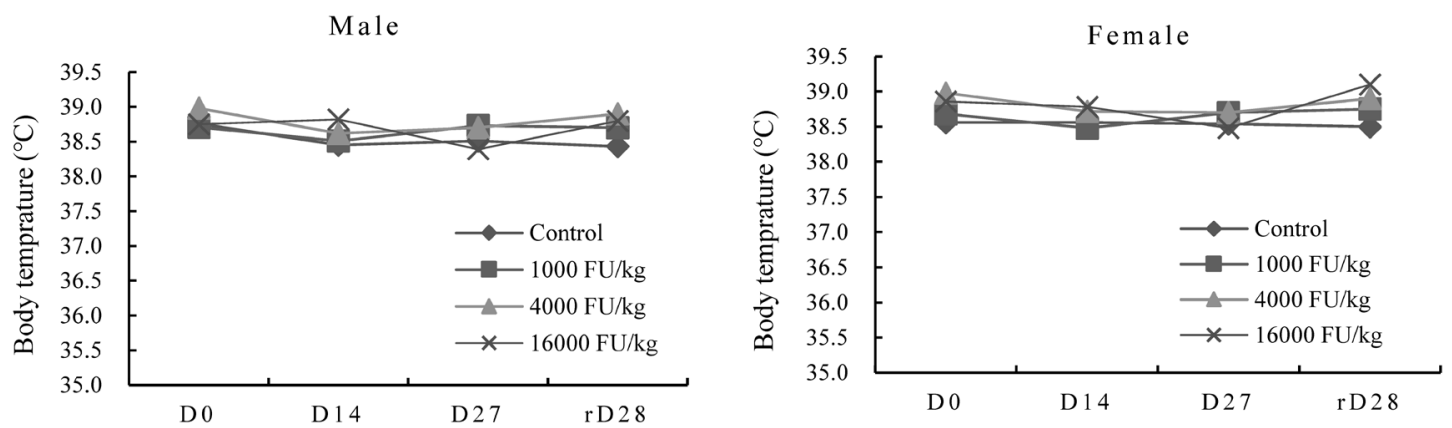

Fig. 3. Mean Body Temperature of Beagle Dogs Administration with Subtilisin QK for $28 \mathrm{~d}$ and $28 \mathrm{~d}$ Recovery 
$(p>0.01)$, the ANOVA results were directly used to determine the statistical significance of the overall difference. If the variance was not uniform ( $p \leq 0.01)$, the statistical significance of the overall difference was judged using results from the Welch test. If the ANOVA or Welch test results were statistically significant, multiple comparisons of differences between groups were performed using the Bonferroni test to further determine which differences between groups were statistically significant. $p<0.05$ was considered statistically significant.

\section{RESULTS}

Acute Toxicity Study During the 14-d observation period, no animals died. Soft stool was observed in 1 female in the $40000 \mathrm{FU} / \mathrm{kg} / \mathrm{d}$ group on the dosing day. The body weights of the females in the control and $40000 \mathrm{FU} / \mathrm{kg} / \mathrm{d}$ groups were slightly decreased. No obvious abnormalities in body temperature, electrocardiogram, haematology, blood biochemistry and coagulation parameters were observed in the dosing and control groups. Similarly, macroscopic examinations revealed no significant pathological changes. (Supplementary Tables 3-8)

\section{Subchronic Toxicity Study}

Clinical Observations and Measurement

During the 28-d dosing or recovery periods, no animals died. Soft stool was occasionally found in the dosing and control groups. In comparison with the control groups, there were no significant differences in the mean body weights, mean food consumption, and mean body temperatures of animal in the dosing groups (Figs. 1-3).

Ophthalmoscopy and ECG

No obvious abnormality was observed in the eyes of all animals' (data not shown). Similarly, there were no statistically significant differences between the ECG of the dosing and control groups on D0, D14, D28, and rD28 (Supplementary Table 9).

Clinical Testing

Table 1a. Coagulation Parameters of Male Beagle Dogs Administration with Subtilisin QK for 28d and 28d Recovery (Mean \pm S.D.)

\begin{tabular}{|c|c|c|c|c|c|}
\hline Time & Groups (FU/kg) & PT (s) & APTT (s) & TT (s) & $\mathrm{FIB}(\mathrm{g} / \mathrm{L})$ \\
\hline \multirow[t]{4}{*}{ D0 $n=5$} & 0 & $8.14 \pm 0.58$ & $32.3 \pm 12.36$ & $12.84 \pm 0.49$ & $2.77 \pm 0.62$ \\
\hline & 1000 & $7.68 \pm 0.27$ & $27.44 \pm 3.08$ & $12.64 \pm 0.48$ & $1.91 \pm 0.41$ \\
\hline & 4000 & $7.56 \pm 0.16$ & $29.38 \pm 5.96$ & $12.64 \pm 0.87$ & $2.21 \pm 0.35$ \\
\hline & 16000 & $7.82 \pm 0.42$ & $30.38 \pm 7.12$ & $11.96 \pm 0.45$ & $2.39 \pm 0.55$ \\
\hline \multirow[t]{4}{*}{$\mathrm{D} 14 n=5$} & 0 & $8.50 \pm 0.55$ & $36.06 \pm 11.71$ & $12.76 \pm 0.66$ & $3.29 \pm 0.70$ \\
\hline & 1000 & $8.04 \pm 0.16$ & $32.86 \pm 5.03$ & $12.86 \pm 0.67$ & $1.99 \pm 0.17 *$ \\
\hline & 4000 & $7.72 \pm 0.22 *$ & $33.68 \pm 9.02$ & $12.52 \pm 0.55$ & $2.49 \pm 0.42$ \\
\hline & 16000 & $8.00 \pm 0.42$ & $32.70 \pm 9.69$ & $12.04 \pm 0.60$ & $2.55 \pm 0.49$ \\
\hline \multirow[t]{4}{*}{$\mathrm{D} 28 n=5$} & 0 & $8.34 \pm 0.65$ & $35.30 \pm 11.60$ & $12.82 \pm 0.77$ & $2.59 \pm 0.51$ \\
\hline & 1000 & $7.64 \pm 0.13$ & $25.82 \pm 4.30$ & $12.74 \pm 0.63$ & $1.90 \pm 0.17$ \\
\hline & 4000 & $7.38 \pm 0.19 *$ & $25.88 \pm 5.68$ & $11.90 \pm 0.59$ & $2.49 \pm 0.41$ \\
\hline & 16000 & $7.96 \pm 0.24$ & $23.86 \pm 3.72$ & $12.26 \pm 0.4$ & $2.05 \pm 0.38$ \\
\hline \multirow[t]{4}{*}{$\mathrm{rD} 28 n=2$} & 0 & 8.35 & 24.9 & 12.3 & 2.34 \\
\hline & 1000 & 7.6 & 19.25 & 12 & 1.715 \\
\hline & 4000 & 7.6 & 22.2 & 12.65 & 1.835 \\
\hline & 16000 & 8.05 & 23 & 12.7 & 1.97 \\
\hline
\end{tabular}

$* p<0.05$ compared to the control group. TT, Thrombin time; PT, Prothrombin time; FIB, Fibrinogen; APTT, Activated partial thromboplastin time; S.D., Standard deviation.

Table 1b. Coagulation Parameters of Female Beagle Dogs Administration with Subtilisin QK for 28d and 28d Recovery (Mean \pm S.D.)

\begin{tabular}{|c|c|c|c|c|c|}
\hline Time & Groups (FU/kg) & PT (s) & APTT (s) & $\mathrm{TT}(\mathrm{s})$ & $\mathrm{FIB}(\mathrm{g} / \mathrm{L})$ \\
\hline \multirow{4}{*}{ D0 $n=5$} & 0 & $7.82 \pm 0.37$ & $29.54 \pm 7.02$ & $12.84 \pm 0.65$ & $2.19 \pm 0.49$ \\
\hline & 1000 & $7.78 \pm 0.42$ & $31.34 \pm 5.82$ & $13.02 \pm 0.52$ & $2.16 \pm 0.31$ \\
\hline & 4000 & $7.72 \pm 0.25$ & $24.78 \pm 1.93$ & $13.18 \pm 1.03$ & $1.97 \pm 0.50$ \\
\hline & 16000 & $7.78 \pm 0.38$ & $25.56 \pm 3.64$ & $12.62 \pm 0.58$ & $2.47 \pm 0.70$ \\
\hline \multirow[t]{4}{*}{$\mathrm{D} 14 n=5$} & 0 & $7.90 \pm 0.33$ & $35.00 \pm 13.28$ & $12.72 \pm 0.56$ & $2.34 \pm 0.34$ \\
\hline & 1000 & $7.74 \pm 0.53$ & $36.88 \pm 15.30$ & $12.56 \pm 0.33$ & $2.94 \pm 0.97$ \\
\hline & 4000 & $7.50 \pm 0.14$ & $23.80 \pm 1.60$ & $12.70 \pm 0.65$ & $2.70 \pm 1.04$ \\
\hline & 16000 & $8.16 \pm 0.49$ & $23.84 \pm 7.08$ & $13.44 \pm 0.39$ & $2.03 \pm 0.50$ \\
\hline \multirow[t]{4}{*}{$\mathrm{D} 28 n=5$} & 0 & $7.72 \pm 0.28$ & $26.30 \pm 7.24$ & $12.56 \pm 0.48$ & $2.03 \pm 0.44$ \\
\hline & 1000 & $7.60 \pm 0.58$ & $33.84 \pm 11.95$ & $13.10 \pm 0.78$ & $2.23 \pm 0.41$ \\
\hline & 4000 & $7.56 \pm 0.27$ & $22.52 \pm 1.41$ & $12.80 \pm 1.03$ & $2.51 \pm 0.84$ \\
\hline & 16000 & $8.06 \pm 0.35$ & $23.22 \pm 6.95$ & $13.48 \pm 0.47$ & $1.99 \pm 0.74$ \\
\hline \multirow[t]{4}{*}{$\mathrm{rD} 28 n=2$} & 0 & 8.05 & 22.55 & 13.15 & 2.06 \\
\hline & 1000 & 7.45 & 26.95 & 13.7 & 1.915 \\
\hline & 4000 & 7.45 & 22.85 & 13.7 & 2.285 \\
\hline & 16000 & 8.15 & 26.5 & 13.9 & 2.83 \\
\hline
\end{tabular}


There were no significant differences in the urinalysis results of the dosing and control groups (data not shown). Compared with the control group, there was a statistically significant shortening of prothrombin time (PT) in the $4000 \mathrm{FU} / \mathrm{kg} / \mathrm{d}$ group males on D14 and D28 $(p<0.05)$, but similar with the pre-dosing data of themselves. The fibrinogen (FIB) values in the $1000 \mathrm{FU} / \mathrm{kg} / \mathrm{d}$ group males on D14 were slightly shorter than those in the control group (Table 1a). There were statistically significant decreases in the reticulocyte ratio (RET \%) of the 4000 and $16000 \mathrm{FU} / \mathrm{kg} / \mathrm{d}$ group males on D28, and eosinophil ratio (EO \%) was increased in the $16000 \mathrm{FU} / \mathrm{kg} / \mathrm{d}$ group males on D28, compared with the control group $(p<0.05)$, but not statistically significant difference with their own previous data (Supplementary Table 10a). Total bilirubin (TBIL) was reduced in the $4000 \mathrm{FU} / \mathrm{kg} / \mathrm{d}$ group males on D0, and triglycerid (TG) was increased in the $1000 \mathrm{FU} / \mathrm{kg} / \mathrm{d}$ group males on D28, compared with the control group $(p<0.05)$ (Supplementary Table 11a). The other coagulation, haematological, blood biochemistry parameters were similar between the control and the dosing groups, implying subtilisin $\mathrm{QK}$ induced no obvious abnormal changes. Therefore, these outcomes were not considered subtilisin QK treatment related.

Organ Weights and Microscopic Findings

At the end of the dosing and recovery periods, 24 and 16 beagle dogs were separately examined, respectively. At the end of the dosing period, the mean absolute and relative ovarian weight in the $1000 \mathrm{FU} / \mathrm{kg} / \mathrm{d}$ group females and control groups were significantly different $(p<0.05)$. But there was no significant difference in the 4000 and $16000 \mathrm{FU} / \mathrm{kg} / \mathrm{d}$ group females relative to controls. Therefore, these outcomes were not considered subtilisin QK treatment related (Table 2b). Compared with control group, there were significant increases in the mean absolute and relative uterine weight of the 1000 $\mathrm{FU} / \mathrm{kg} / \mathrm{d}$ group females, but not statically significant difference (Table 2b). These findings were not considered to be related to subtilisin QK treatment. Additionally, there were no statistically significant differences in other organs between the doing and control groups (Table 3).

Histopathology

The histopathology results of the control $(0 \mathrm{FU} / \mathrm{kg} / \mathrm{d})$, low dose $(1000 \mathrm{FU} / \mathrm{kg} / \mathrm{d})$, middle dose $(4000 \mathrm{FU} / \mathrm{kg} / \mathrm{d})$, and high dose $(16000 \mathrm{FU} / \mathrm{kg} / \mathrm{d})$ groups are shown in supplementary table 12. The pathological changes were considered spontaneous or sporadic because the background lesions of the beagle dogs in the control, low dose, middle dose, and high dose groups were not significantly related to subtilisin QK. In addition, no abnormal bone marrow was observed in any of the animals.

Immunotoxicity

There were no statistically significant differences in serum immune parameters, peripheral blood $\mathrm{T}$ lymphocyte, and $\mathrm{T}$ lymphocyte typing of all treatment groups (Supplementary Table 13). A female beagle in the $16000 \mathrm{FU} / \mathrm{kg} / \mathrm{d}$ dose group had a mild atrophy of the thymus. However, histopathological

Table 2a. Absolute Mean Organ Weights of Male Beagle Dogs Administration with Subtilisin QK for 28d and 28d Recovery (Mean \pm S.D.)

\begin{tabular}{|c|c|c|c|c|c|c|c|c|}
\hline & \multicolumn{4}{|c|}{$\mathrm{D} 29(n=3)$} & \multicolumn{4}{|c|}{$\operatorname{rD} 29(n=2)$} \\
\hline & $0 \mathrm{FU} / \mathrm{kg}$ & $1000 \mathrm{FU} / \mathrm{kg}$ & $4000 \mathrm{FU} / \mathrm{kg}$ & $16000 \mathrm{FU} / \mathrm{kg}$ & $0 \mathrm{FU} / \mathrm{kg}$ & $1000 \mathrm{FU} / \mathrm{kg}$ & $4000 \mathrm{FU} / \mathrm{kg}$ & $16000 \mathrm{FU} / \mathrm{kg}$ \\
\hline Heart & $76.83 \pm 6.02$ & $79.57 \pm 6.36$ & $77.71 \pm 4.32$ & $72.39 \pm 8.09$ & 77.73 & 81.20 & 75.82 & 79.79 \\
\hline Liver & $274.05 \pm 27.20$ & $253.68 \pm 17.73$ & $264.00 \pm 7.69$ & $287.40 \pm 28.11$ & 267.81 & 257.99 & 254.44 & 286.84 \\
\hline Spleen & $30.15 \pm 11.01$ & $31.17 \pm 3.78$ & $26.57 \pm 0.77$ & $27.05 \pm 5.19$ & 30.49 & 37.40 & 27.35 & 28.91 \\
\hline Kidenys & $47.73 \pm 10.3$ & $38.80 \pm 4.87$ & $45.36 \pm 9.06$ & $49.43 \pm 6.07$ & 56.36 & 48.85 & 41.36 & 42.04 \\
\hline Thymus & $15.79 \pm 4.99$ & $16.50 \pm 2.33$ & $18.26 \pm 2.56$ & $17.65 \pm 1.97$ & 16.30 & 17.40 & 15.22 & 21.18 \\
\hline Adrenals & $1.10 \pm 0.17$ & $0.94 \pm 0.01$ & $1.07 \pm 0.20$ & $1.18 \pm 0.21$ & 1.33 & 1.48 & 1.10 & 1.12 \\
\hline Thyroid & $1.23 \pm 0.33$ & $0.74 \pm 0.16$ & $0.98 \pm 0.08$ & $1.38 \pm 0.26$ & 1.07 & 1.20 & 0.82 & 0.84 \\
\hline Testis & $5.35 \pm 3.54$ & $9.18 \pm 0.80$ & $7.12 \pm 2.25$ & $9.68 \pm 6.42$ & 14.46 & 14.26 & 14.40 & 14.52 \\
\hline Epididymis & $2.53 \pm 1.20$ & $2.29 \pm 0.41$ & $1.68 \pm 0.10$ & $2.05 \pm 0.75$ & 3.00 & 2.99 & 3.47 & 3.09 \\
\hline Brain & $80.44 \pm 4.43$ & $80.23 \pm 1.37$ & $82.92 \pm 7.41$ & $76.64 \pm 4.93$ & 87.10 & 81.82 & 77.91 & 72.54 \\
\hline
\end{tabular}

${ }^{*} p<0.05$ compared to the control group. S.D., Standard deviation.

Table 2b. Absolute Mean Organ Weights of Female Beagle Dogs Administration with Subtilisin QK for 28d and 28d Recovery (Mean \pm S.D.)

\begin{tabular}{|c|c|c|c|c|c|c|c|c|}
\hline & \multicolumn{4}{|c|}{$\mathrm{D} 29(n=3)$} & \multicolumn{4}{|c|}{$\operatorname{rD} 29(n=2)$} \\
\hline & $0 \mathrm{FU} / \mathrm{kg}$ & $1000 \mathrm{FU} / \mathrm{kg}$ & $4000 \mathrm{FU} / \mathrm{kg}$ & $16000 \mathrm{FU} / \mathrm{kg}$ & $0 \mathrm{FU} / \mathrm{kg}$ & $1000 \mathrm{FU} / \mathrm{kg}$ & $4000 \mathrm{FU} / \mathrm{kg}$ & $16000 \mathrm{FU} / \mathrm{kg}$ \\
\hline Heart & $70.37 \pm 5.90$ & $71.83 \pm 10.11$ & $73.34 \pm 7.29$ & $71.26 \pm 7.16$ & 73.72 & 67.74 & 72.57 & 70.46 \\
\hline Liver & $213.52 \pm 25.05$ & $224.76 \pm 13.78$ & $216.97 \pm 29.93$ & $207.68 \pm 17.05$ & 227.63 & 238.56 & 232.69 & 238.50 \\
\hline Spleen & $26.67 \pm 3.52$ & $33.76 \pm 11.03$ & $33.35 \pm 8.28$ & $26.11 \pm 6.91$ & 24.11 & 27.89 & 31.31 & 39.48 \\
\hline Kidenys & $39.86 \pm 4.75$ & $39.86 \pm 7.35$ & $42.07 \pm 5.44$ & $33.88 \pm 4.73$ & 42.24 & 38.63 & 39.06 & 35.82 \\
\hline Thymus & $11.54 \pm 6.74$ & $12.49 \pm 9.80$ & $12.44 \pm 1.68$ & $7.92 \pm 5.53$ & 11.14 & 15.26 & 12.55 & 15.79 \\
\hline Adrenals & $1.18 \pm 0.10$ & $1.30 \pm 0.26$ & $1.10 \pm 0.05$ & $1.04 \pm 0.05$ & 1.28 & 1.22 & 1.25 & 1.21 \\
\hline Thyroid & $1.00 \pm 0.43$ & $1.12 \pm 0.44$ & $0.92 \pm 0.10$ & $0.75 \pm 0.30$ & 0.86 & 0.92 & 0.92 & 0.91 \\
\hline Uterus & $2.88 \pm 1.73$ & $8.84 \pm 7.70$ & $2.90 \pm 0.42$ & $2.45 \pm 0.30$ & 2.19 & 2.07 & 2.52 & 2.08 \\
\hline Ovaries & $0.59 \pm 0.08$ & $1.12 \pm 0.26 *$ & $0.86 \pm 0.13$ & $0.68 \pm 0.11$ & 0.84 & 0.55 & 0.84 & 0.63 \\
\hline Brain & $77.33 \pm 5.17$ & $73.91 \pm 2.75$ & $77.10 \pm 12.76$ & $73.59 \pm 5.03$ & 68.56 & 78.65 & 76.51 & 78.95 \\
\hline
\end{tabular}

$* p<0.05$ compared to the control group. S.D., Standard deviation. 
Table 3a. Relative Mean Organ Weights of Male Beagle Dogs Administration with Subtilisin QK for 28d and 28d Recovery (Mean \pm S.D.)

\begin{tabular}{|c|c|c|c|c|c|c|c|c|}
\hline & \multicolumn{4}{|c|}{$\mathrm{D} 29(n=3)$} & \multicolumn{4}{|c|}{$\operatorname{rD} 29(n=2)$} \\
\hline & $0 \mathrm{FU} / \mathrm{kg}$ & $1000 \mathrm{FU} / \mathrm{kg}$ & $4000 \mathrm{FU} / \mathrm{kg}$ & $16000 \mathrm{FU} / \mathrm{kg}$ & $0 \mathrm{FU} / \mathrm{kg}$ & $1000 \mathrm{FU} / \mathrm{kg}$ & $4000 \mathrm{FU} / \mathrm{kg}$ & $16000 \mathrm{FU} / \mathrm{kg}$ \\
\hline Heart & $7.62 \pm 0.70$ & $8.12 \pm 1.88$ & $7.58 \pm 0.48$ & $6.77 \pm 0.50$ & 7.17 & 7.43 & 7.14 & 7.39 \\
\hline Liver & $27.22 \pm 3.07$ & $25.56 \pm 2.56$ & $25.81 \pm 2.30$ & $27.05 \pm 3.82$ & 24.43 & 23.55 & 23.88 & 26.64 \\
\hline Spleen & $3.03 \pm 1.31$ & $3.13 \pm 0.29$ & $2.59 \pm 0.22$ & $2.52 \pm 0.40$ & 2.82 & 3.42 & 2.56 & 2.64 \\
\hline Kidenys & $4.74 \pm 1.06$ & $3.91 \pm 0.64$ & $4.37 \pm 0.35$ & $4.65 \pm 0.79$ & 5.20 & 4.46 & 3.89 & 3.86 \\
\hline Thymus & $1.55 \pm 0.45$ & $1.67 \pm 0.40$ & $1.77 \pm 0.08$ & $1.66 \pm 0.26$ & 1.45 & 1.59 & 1.42 & 1.96 \\
\hline Adrenals & $0.11 \pm 0.02$ & $0.09 \pm 0.01$ & $0.10 \pm 0.01$ & $0.11 \pm 0.02$ & 0.12 & 0.13 & 0.10 & 0.10 \\
\hline Thyroid & $0.19 \pm 0.16$ & $0.07 \pm 0.01$ & $0.09 \pm 0.01$ & $0.12 \pm 0.02$ & 0.09 & 0.10 & 0.07 & 0.07 \\
\hline Testis & $0.51 \pm 0.30$ & $0.92 \pm 0.10$ & $0.71 \pm 0.30$ & $0.9 \pm 0.57$ & 1.41 & 1.30 & 1.35 & 1.32 \\
\hline Epididymis & $0.25 \pm 0.14$ & $0.22 \pm 0.02$ & $0.16 \pm 0.02$ & $0.19 \pm 0.06$ & 0.28 & 0.27 & 0.32 & 0.28 \\
\hline Brain & $7.97 \pm 0.25$ & $8.13 \pm 1.24$ & $8.06 \pm 0.23$ & $7.21 \pm 0.81$ & 8.11 & 7.46 & 7.31 & 6.71 \\
\hline
\end{tabular}

${ }^{*} p<0.05$ compared to the control group. S.D., Standard deviation.

Table 3b. Relative Mean Organ Weights of Female Beagle Dogs Administration with Subtilisin QK for 28d and 28d Recovery (Mean \pm S.D.)

\begin{tabular}{|c|c|c|c|c|c|c|c|c|}
\hline & \multicolumn{4}{|c|}{$\mathrm{D} 29(n=3)$} & \multicolumn{4}{|c|}{$\operatorname{rD} 29(n=2)$} \\
\hline & $0 \mathrm{FU} / \mathrm{kg}$ & $1000 \mathrm{FU} / \mathrm{kg}$ & $4000 \mathrm{FU} / \mathrm{kg}$ & $16000 \mathrm{FU} / \mathrm{kg}$ & $0 \mathrm{FU} / \mathrm{kg}$ & $1000 \mathrm{FU} / \mathrm{kg}$ & $4000 \mathrm{FU} / \mathrm{kg}$ & $16000 \mathrm{FU} / \mathrm{kg}$ \\
\hline Heart & $8.14 \pm 1.16$ & $7.79 \pm 0.13$ & $8.13 \pm 0.36$ & $8.24 \pm 0.17$ & 7.59 & 6.68 & 7.98 & 6.85 \\
\hline Liver & $24.65 \pm 3.35$ & $24.60 \pm 2.58$ & $23.99 \pm 1.49$ & $24.05 \pm 0.60$ & 23.20 & 23.60 & 25.49 & 23.13 \\
\hline Spleen & $3.08 \pm 0.53$ & $3.63 \pm 0.82$ & $3.67 \pm 0.66$ & $3.01 \pm 0.73$ & 2.48 & 2.76 & 3.51 & 3.84 \\
\hline Kidenys & $4.61 \pm 0.71$ & $4.30 \pm 0.19$ & $4.65 \pm 0.18$ & $3.91 \pm 0.25$ & 4.31 & 3.83 & 4.30 & 3.47 \\
\hline Thymus & $1.27 \pm 0.56$ & $1.40 \pm 1.05$ & $1.37 \pm 0.04$ & $0.88 \pm 0.59$ & 1.15 & 1.51 & 1.41 & 1.52 \\
\hline Adrenals & $0.13 \pm 0.03$ & $0.14 \pm 0.04$ & $0.12 \pm 0.00$ & $0.12 \pm 0.00$ & 0.13 & 0.12 & 0.13 & 0.11 \\
\hline Thyroid & $0.11 \pm 0.04$ & $0.12 \pm 0.03$ & $0.10 \pm 0.00$ & $0.08 \pm 0.03$ & 0.08 & 0.09 & 0.10 & 0.08 \\
\hline Uterus & $0.33 \pm 0.16$ & $0.95 \pm 0.74$ & $0.33 \pm 0.08$ & $0.29 \pm 0.05$ & 0.22 & 0.20 & 0.28 & 0.20 \\
\hline Ovaries & $0.07 \pm 0.01$ & $0.12 \pm 0.04 *$ & $0.09 \pm 0.03$ & $0.08 \pm 0.01$ & 0.08 & 0.05 & 0.09 & 0.06 \\
\hline Brain & $9.06 \pm 2.17$ & $8.15 \pm 1.43$ & $8.71 \pm 2.50$ & $8.57 \pm 1.04$ & 7.06 & 7.78 & 8.45 & 7.67 \\
\hline
\end{tabular}

$*_{p}<0.05$ compared to the control group. S.D., Standard deviation.

examinations showed no obvious abnormalities in the thymus, and there were no significant differences in the relevant biochemical indicators. Additionally, no pathological damages were observed in thymus, spleen and lymph nodes (mesenteric and submandibular lymph nodes). Therefore, this finding was not considered to be related to subtilisin QK treatment.

Safety Pharmacology Study During the 4 dosing periods, no animals died, and no obvious clinical symptoms were observed in the animals of each group. Compared with the pre-treatment data and those of the control group, there were no statistically significant changes in the electrocardiogram (heart rate, PR interval, QT interval, QRS interval, $\mathrm{P}$ wave, $\mathrm{R}$ wave, T wave, ST segment, and QTc values), blood pressure (systolic blood pressure, diastolic blood pressure, and average pressure), and respiratory parameters (respiratory frequency and tidal volume) of the dosing groups (Supplementary Tables 14, 15).

\section{DISCUSSION}

At present, thrombotic vascular diseases are severe and safe and effective oral thrombolytic drugs are lacking. Many fibrinolytic enzymes such as urokinase, streptokinase, and t-PA, reportedly have good thrombolytic effects. ${ }^{23,24)}$ However, treatment with those agents is accompanied by adverse effects, such as bleeding. ${ }^{25}$ ) Therefore, they are not suitable for the long-term prevention and treatment of cardiovascu- lar and cerebrovascular thrombotic diseases. The effects of Bacillus subtilisin in diseases such as thrombosis, hyperlipemia, hypertension, and atherosclerosis have been extensively studied. ${ }^{26-28)}$ Specifically, in thrombosis-related diseases, their advantages include an excellent thrombolytic effect, high specificity, and few side effects. Therefore, Bacillus subtilisins are natural oral thrombolytic proteins with significant development potential. Although Chinese Dou-chi, Japanese natto, Korean Chunggok-Jang, and Indian kinema have been used as food for $>1000$ years with no incidence of adverse effects, ${ }^{20)}$ the toxicological data of Bacillus subtilisin remain limited.

The toxicity of subtilisin NAT in mice and Sprague-Dawley (SD) rats has recently been reported. A single oral administration of $49400 \mathrm{FU} / \mathrm{kg}$ subtilisin NAT to rats resulted in no animal deaths and no obvious pathological changes after $14 \mathrm{~d} .^{19)}$ Moreover, daily administration of $480000 \mathrm{FU} / \mathrm{kg}$ subtilisin NAT to mice for $4 \mathrm{~d}$ reportedly resulted in no obvious toxicity. ${ }^{29)}$ Additionally, daily administration of $3340 \mathrm{FU} / \mathrm{kg}$ subtilisin NAT to rats for $28 \mathrm{~d}$ had no significant effects on their urinalysis and histopathological examination results. ${ }^{19}$ ) Furthermore, daily administration of $21900 \mathrm{FU} / \mathrm{kg}$ subtilisin NAT to rats for $90 \mathrm{~d}$ caused no significant toxicity. ${ }^{19)}$ However, it was reported that the use of rodent for predicting human toxicity with a concordance rate of $43 \%{ }^{30}$ ) The assessment of the safety of Bacillus subtilisin is limited by the lack of information on its toxicity in non-rodents. Therefore, in the present study, we conducted a series of safety assessment experiments 
with subtilisin QK in beagle dogs, to elucidate the safety of Bacillus subtilisin.

For the present study, a single dose of $40000 \mathrm{FU} / \mathrm{kg}$ subtilisin QK to beagle dogs results in no adverse effects. Subsequently, to observe the toxicity and dose-response relationship of subtilisin QK, beagle dogs were administrated daily dose at $0,1000,4000$, and $16000 \mathrm{FU} / \mathrm{kg}$ for $28 \mathrm{~d}$. Compared with the control groups, there were statistically significant increase in the EO \% of the $16000 \mathrm{FU} / \mathrm{kg} / \mathrm{d}$ group males on D28 $(p<0.05)$. However, there were no adverse clinical signs and no abnormal $\mathrm{IgG}$ or $\operatorname{IgM}$ in the $16000 \mathrm{FU} / \mathrm{kg} / \mathrm{d}$ group (Supplementary Table 13). In addition, compared with the control groups, the body weights, food consumption, and body temperatures of the $16000 \mathrm{FU} / \mathrm{kg}$ groups were normal (Figs. 1-3). There was also no abnormal in the acute toxicity study. Besides, in another study of subchronic toxicity in rats, we used a large number of rats, but eosinophil levels were not abnormal (data not published). Therefore, it is almost impossible for subtilisin QK to cause food allergies. These results indicated that the maximum dose of subtilisin QK had no significant toxic effect in this study. The results were similar to those obtained post repeated dosing of subtilisin NAT in rats and mice. ${ }^{19,29)}$ To observe the reversibility of toxic effects and possible delayed toxicity, 16 beagle dogs were continually monitored for $28 \mathrm{~d}$ after the $28 \mathrm{~d}$ repeated administration period and no delayed toxicity was observed. Furthermore, subtilisin QK cause no significant immunotoxicity effects in beagle dogs. Due to the lack of adverse effects during the acute and subchronic toxicity studies, we conducted safety pharmacology studies in the beagle dogs.

Safety pharmacology studies are used to determine the predicted and unpredicted side effects of drugs. Generally, the safety pharmacology core battery of tests that must be completed, including the central nervous, cardiovascular and respiratory systems. ${ }^{31)}$ Thus, the emka PACK 4G telemetry system was used to detect the ECG, blood pressure, and respiration of the beagle dogs. Compared with the pre-dosing data and those of the control group, there were no significant differences between the QT and QTc interval of all dosing groups. Moreover, the blood pressure and respiration of the treated dogs were not significantly affected. Based on these findings, the maximum dose of subtilisin QK used in the acute toxicity, 28-d toxicity, and the safety pharmacology studies were up to 40000,16000 , and $2000 \mathrm{FU} / \mathrm{kg}$, which were about 200, 80, and 10 times higher than the equivalent dose of Beagle dog (about $200 \mathrm{FU} / \mathrm{kg}$ ), respectively. Despite this, there were no significant physiological changes and toxic (tissue and organ) effects in the subtilisin QK-treated dose groups.

\section{CONCLUSION}

In summary, Bacillus subtilisin is a popular functional food with great potential in cardiovascular and cerebrovascular disease prevention and treatment. Subtilisin QK, a Bacillus subtilisin, also has many potential benefits for humans. In this study, we found that the administration of a single dose of up to $40000 \mathrm{FU} / \mathrm{kg}$, and repeated daily doses of up to 16000 $\mathrm{FU} / \mathrm{kg}$ to male and female beagle dogs resulted in no obvious toxic effects. No adverse effects were observed in the cardiovascular, central nervous, and respiratory systems of beagle dogs post daily administration of up to a dose limit of 2000
$\mathrm{FU} / \mathrm{kg}$ subtilisin QK. Based on these results, the no-observedadverse-effect level (NOAEL) in beagle dogs following a 28- $\mathrm{d}$ repeated dosing exposure to oral subtilisin QK is 16000 $\mathrm{FU} / \mathrm{kg} / \mathrm{d}$.

Acknowledgments We are grateful for the animal experimentation platform provided by the Suzhou Drug Safety Evaluation and Research Centre. This work was supported by the China Postdoctoral Science Foundation (2016M592375), Hubei province's health and family planning scientific research project (WJ2017Q002), the Wuhan Enterprise Technology Innovation Project (2018060402011244).

Author Contributions Yefu Wang conceived the study. Yanshan Dong and Shuai Xiao designed the experiments. Kunkun $\mathrm{Hu}$, Shuai Xiao and Dingbang Hu performed the experiments. Shuai Xiao and Yanshan Dong analyzed the data. Yefu Wang and Shuai Xiao wrote the paper. Yefu Wang, Li Zhou and Yanshan Dong received and revised the paper.

Conflict of Interest The authors declare no conflict of interest.

Supplementary Materials The online version of this article contains supplementary materials.

\section{REFERENCES}

1) Benziger CP, Roth GA, Moran AE. The global burden of disease study and the preventable burden of NCD. Glob. Heart, 11, 393-397 (2016).

2) Tornkvist M, Smith JG, Labaf A. Current evidence of oral anticoagulant rever-sal: a systematic review. Thromb. Res., 162, 22-31 (2018).

3) Fujita M, Nomura K, Hong K, Ito Y, Asada A, Nishimuro S. Purification and characterization of a strong fibrinolytic enzyme (nattokinase) in the vegetable cheese natto, a popular soybean fer-mented food in Japan. Biochem. Biophys. Res. Commun., 197, 1340-1347 (1993).

4) Kim SB, Lee DW, Cheigh CI, Choe EA, Lee SJ, Hong YH, Choi HJ, Pyun YR. Purification and characteriza-tion of a fibrinolytic subtilisin-like protease of Bacillus subtilis TP-6 from an Indonesian fermented soybean, Tempeh. J. Ind. Microbiol. Biotechnol., 33, 436-444 (2006).

5) Peng Y, Yang X, Zhang Y. Microbial fibrinolytic enzymes: an overview of source, production, properties, and thrombolytic activity in vivo. Appl. Microbiol. Biotechnol., 69, 126-132 (2005).

6) Tai MW, Sweet BV. Nattokinase for prevention of thrombosis. Am. J. Health Syst. Pharm., 63, 1121-1123 (2006).

7) Kotb E. The biotechnological potential of fibrinolytic enzymes in the dissolution of endogenous blood thrombi. Biotechnol. Prog., 30, 656-672 (2014)

8) Weng Y, Yao J, Sparks S, Wang K. Nattokinase: an oral antithrombotic agent for the prevention of cardiovascular disease. Int. J. Mol. Sci., 18, 523 (2017).

9) Chen H, McGowan EM, Ren N, Lal S, Nassif N, Shad-Kaneez F, $\mathrm{Qu}$ X, Lin Y. Nattokinase: a promising alternative in prevention and treatment of cardiovascular diseases. Biomark. Insights, 13, 1177271918785130 (2018)

10) Sumi H, Hamada H, Tsushima H, Mihara H, Muraki H. A novel fibrinolytic enzyme (nattokinase) in the vegetable cheese Natto; a typical and popular soy-bean food in the Japanese diet. Experientia, 43, 1110-1111 (1987).

11) Fujita $M$, Ito $Y$, Hong $K$, Nishimuro S. Characterization of natto- 
kinase-degraded products from human fibrinogen or cross-linked fibrin. Fibrinolysis, 9, 157-164 (1995).

12) Fujita $M$, Hong $K$, Ito $Y$, Misawa $S$, Takeuchi $N$, Kariya $K$, Nishimuro S. Transport of nattokinase across the rat intestinal tract. Biol. Pharm. Bull., 18, 1194-1196 (1995).

13) Kamiya $\mathrm{S}$, Hagimori M, Ogasawara $\mathrm{M}$, Arakawa M. In vivo evaluation method of the effect of nattokinase on carrageenan-induced tail thrombosis in a rat model. Acta Haematol., 124, 218-224 (2010).

14) Fujita M, Hong K, Ito Y, Fujii R, Kariya K, Nishimuro S. Thrombolytic effect of nattokinase on a chemically induced thrombosis model in rat. Biol. Pharm. Bull., 18, 1387-1391 (1995).

15) Yatagai C, Maruyama M, Kawahara T, Sumi H. Nattokinasepromoted tissue plasminogen activator release from human cells. Pathophysiol. Haemost. Thromb., 36, 227-232 (2008).

16) Hsia CH, Shen MC, Lin JS, Wen YK, Hwang KL, Cham TM, Yang NC. Nattoki-nase decreases plasma levels of fibrinogen, factor VII, and factor VIII in human subjects. Nutr. Res., 29, 190-196 (2009).

17) DeDea L. The antiplatelet effects of aspirin; nattokinase as a blood thinner. JAAPA, 23, 13 (2010).

18) Kurosawa $Y$, Nirengi $S$, Homma $T$, Esaki $K$, Ohta M, Clark JF, Hamaoka T. A single-dose of oral nattokinase potentiates thrombolysis and anti-coagulation profiles. Sci. Rep., 5, 11601(2015).

19) Lampe BJ, English JC. Toxicological assessment of nattokinase derived from Bacillus subtilis var. natto. Food Chem. Toxicol., 88, 87-99 (2016)

20) Ko JH, Yan JP, Zhu L, Qi YP. Identification of two novel fibrinolytic enzymes from Bacillus subtilis QK02. Comp. Biochem. Physiol. C Toxicol. Pharmacol., 137, 65-74 (2004).

21) Ko JH, Yan JP, Zhu L, Qi YP. Subtilisin QK, a fibrinolytic enzyme, inhibits the exogenous nitrite and hydrogen peroxide induced protein nitration, in vitro and in vivo. J. Biochem. Mol. Biol., 38, 577-583 (2005).

22) Yan F, Yan J, Sun W, Yao L, Wang J, Qi Y, Xu H. Thrombolytic effect of Subtilisin QK on carrageenan induced thrombosis model in mice. J. Thromb. Thrombolysis, 28, 444-448 (2009).

23) Dehmer GJ, Gresalfi N, Daly D, Oberhardt B, Tate DA. Impairment of fibrinolysis by streptokinase, urokinase and recombinant tissuetype plasminogen activator in the presence of radio-graphic contrast agents. J. Am. Coll. Cardiol., 25, 1069-1075 (1995).

24) Broderick JP, Palesch YY, Demchuk AM, et al. Endovascular therapy after intravenous t-PA versus t-PA alone for stroke. $N$. Engl. J. Med., 368, 893-903 (2013).

25) García-Pastor A, Díaz-Otero F, Funes-Molina C, Benito-Conde B, Grandes-Velasco S, Sobrino-García P, Vázquez-Alén P, FernándezBullido Y, Villanueva-Osorio JA, Gil-Núñez A. Tissue plasminogen activator for acute is-chemic stroke: calculation of dose based on estimated patient weight can increase the risk of cerebral bleeding. J. Thromb. Thrombolysis, 40, 347-352 (2015).

26) Kim JY, Gum SN, Paik JK, Lim HH, Kim KC, Ogasawara K, Inoue $\mathrm{K}$, Park S, Jang Y, Lee JH. Effects of nattokinase on blood pressure: a randomized, controlled trial. Hypertens. Res., 31, 1583-1588 (2008).

27) Fujita M, Ohnishi K, Takaoka S, Ogasawara K, Fukuyama R, Nakamuta $\mathrm{H}$. Antihypertensive effects of continuous oral administration of nattokinase and its fragments in spontaneously hypertensive rats. Biol. Pharm. Bull., 34, 1696-1701 (2011).

28) Xu J, Du M, Yang X, Chen Q, Chen H, Lin D. Thrombolytic effects in vivo of nattokinase in a carrageenan-induced rat model of thrombosis. Acta Haematol., 132, 247-253 (2014).

29) Wu H, Wang H, Xu F, Chen J, Duan L, Zhang F. Acute toxicity and genotoxicity evaluations of Nattokinase, a promising agent for cardiovascular diseases prevention. Regul. Toxicol. Pharmacol., 103, 205-209 (2019).

30) Olson H, Betton G, Robinson D, Thomas K, Monro A, Kolaja G, Lilly P, Sanders J, Sipes G, Bracken W, Dorato M, Van Deun K, Smith P, Berger B, Heller A. Concordance of the Toxicity of Pharmaceuticals in Humans and in Animals. Regul. Toxicol. Pharmacol., 32, 56-67 (2000).

31) Morimoto BH, Castelloe E, Fox AW. Safety pharmacology in drug discovery and development. Handb. Exp. Pharmacol., 229, 65-80 (2015). 